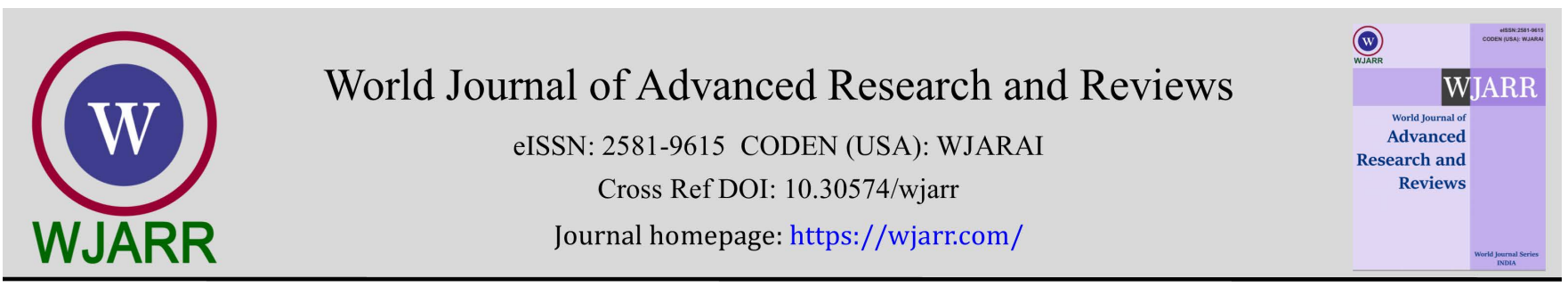

(RESEARCh ARTICLE)

\title{
Role of biomarkers in predicting prognosis of Coronavirus disease 2019 (COVID-19): A retrospective cross-sectional study: Perspective of a tertiary care hospital in India
}

\author{
Arushi Mohan, Padmini SN, Brunda MS *, Abhinaya Shekhar, Paul Matthew and G.R. Lingeshwaran \\ Internal medicine, Aster CMI hospital Bengaluru, Karnataka, India
}

World Journal of Advanced Research and Reviews, 2021, 11(01), 081-090

Publication history: Received on 24 May 2021; revised on 26 June 2021; accepted on 29 June 2021

Article DOI: https://doi.org/10.30574/wjarr.2021.11.1.0300

\begin{abstract}
Background: COVID-19 is a novel disease triggered by the SARS-CoV-2 virus, a beta coronavirus similar to MERS-CoV and SARS CoV. Inflammatory markers have a vital role in the pathogenesis of nCOVID 19; understanding the importance of these inflammatory markers in determining disease status is essential given the impact of the disease on healthcare. Thus, being able to triage cases with minimal tests is momentous to capture, which we have investigated as per our study guidelines of the role of inflammatory markers such as D-dimer, CRP (C - reactive protein), Ferritin, LDH (Lactate Dehydrogenase) in patients with COVID 19. In addition, limited data is available comparing the utility of these inflammatory markers to predict the following parameters as the need for ICU, oxygen support requirement, and duration of in-hospital stay, which can help guide the management protocol.
\end{abstract}

Aim: This study aims to determine markers associated with poor prognosis in patients with Coronavirus disease 2019 (COVID-19).

Objectives: 1) To assess the inflammatory markers that are routinely investigated in COVID- 19 patients.

2) To determine the most probable factor to estimate severity in COVID- 19 and thus predict prognosis.

Methods: This is a retrospective cross-sectional observational study of patients who tested SARS COV 2 positive by RT PCR. The laboratory inflammatory markers, namely Lactate Dehydrogenase, C reactive protein, D-dimer, Ferritin, were assessed in the selected patients, and their clinical data and demographic details were taken into account. The parameters considered for contributing to the severity included the number of days of stay in the hospital, oxygen requirement, and ICU needs. Analyses relied upon analysis of variance for cross-sectional study design and a $\mathrm{P}<0.05$ statistical significance criterion.

Results: There was a statistically significant difference found between oxygen requirement and D dimer ( $\mathrm{p}<0.001), \mathrm{LDH}$ $(p=0.002)$, and CRP ( $p=0.024)$. There was a statistically significant difference found between admission to ICU and D Dimer $(\mathrm{p}=0.001)$.

Conclusion: A statistically significant association between the increasing D-dimer levels and all the outcome measures considered was found. The D-dimer, LDH, and CRP help predict oxygen requirement, and all the inflammatory markers can predict the number of days of stay in the hospital.

Keywords: D-dimer; C-Reactive Protein; Ferritin; Lactate Dehydrogenase; Intensive Care Units; COVID-19

\footnotetext{
* Corresponding author: Arushi Mohan

Internal medicine, Aster CMI hospital Bengaluru, Karnataka, India

Copyright (@ 2021 Author(s) retain the copyright of this article. This article is published under the terms of the Creative Commons Attribution Liscense 4.0.
} 


\section{Introduction}

COVID-19 is a new disease triggered by a novel coronavirus. The SARS-CoV-2 virus is a beta coronavirus, like MERS-CoV and SARS-CoV. COVID-19 was first identified in Wuhan, China, in December 2019. It was stated a pandemic by WHO on January 11, 2020.

The first phase of infection is viral replication, which manifests as mild fever symptoms, upper respiratory tract symptoms, and systemic features such as myalgia. This is followed by a cytokine response mediated by immunoglobulins where there is excessive damage to the alveoli with the predominance of the inflammatory phase. Finally, a third of patients enter an overwhelming phase of ARDS characterized by severe lung inflammation.

Clinical deterioration usually occurs 7-10 days after the onset of symptoms, corresponding with declining viral titers, suggesting that the pathogenesis is driven by inflammation rather than direct viral injury [1]. Inflammatory markers are often substantially elevated in patients with severe COVID-19. Uncontrolled, self-perpetuating, and tissue-damaging inflammatory activity (hyper inflammation) has also been described previously in the pathogenesis of other human coronavirus infections.

Biomarkers play a vital role in identifying mild, moderate-severe cases more objectively. The significant rise in Ferritin, C-Reactive Protein, and interleukin-6 (IL-6) levels reflects monocyte-macrophage activation resulting in an inflammatory storm and cytokine storm.[1]. The cytokine IL-6, with its expression time longer than others has been reported to be better predictor of disease progression [1,2]. In addition, it is known that during an inflammatory storm, as a result of plasmin activation, the significant rise in D-dimer level indicates hypercoagulability. [3,4] Lymphopenia as a dysregulation in the immune response is mapped through more decrease in T cell and T helper cells in severe cases of COVID-19 [5].

Serious adverse health outcome of COVID-19 infection was found much more predominant among children, especially those below 12 years, the elderly population, and patients with co morbid diseases. [4,6]

Ferritin helps protect the host body system against active infection by restricting iron availability to the pathogen [7,8]. An elevated ferritin level in the blood causes a hyperferritinemia-like condition in patients exposed to very high pathogens. It can also be used as an aim for various therapeutic interventions in clinical practice. The serum ferritin level may be used as a biomarker to determine the pathological condition of nCOVID-19 infection [9,10]. It can also be used as an aim for various therapeutic interventions in clinical practice [10].

C-Reactive Protein is a marker of inflammation/infection, a marker for assessing changes in biomarkers of nutritional status particularly serum ferritin or retinol levels, during infection or inflammation [10,11] C-Reactive Protein is an acute-phase reactant produced by the liver in response to inflammation, infection, and necrosis.

D dimer is released when plasmin cleaves fibrin from a clot. The secretion, as well as intracellular level of fibrinogen, was found to be elevated in the nCOVID-19 patient. It was initially analyzed that nCOVID-19-induced coagulopathy presented with highly elevated D-dimer and degraded products of fibrinogen; the infection may be linked with disseminated intravascular coagulopathy (DIC). Previous studies have also demonstrated the role of D dimer in Community-acquired pneumonia. $[12,13]$.

Lactate Dehydrogenase is an intracellular enzyme that potentiates the conversion of pyruvate to lactate [14]. It is released in response to tissue injury. It is found in various tissues/organs such as heart, liver, lung, kidney-pancreas and striated muscle. There are multiple isoenzymes indicative of various organ systems of which in COVID 19 infection Lactate Dehydrogenase isoenzyme-3 in the lung is released as a part of the cytokine storm [15] in response to the virus resulting in interstitial pneumonia progressing to ARDS [16]. Lactate Dehydrogenase levels have been used to measure survival in various settings including cancer for several years, with higher levels signifying a much worse prognosis.[17] For example, Lactate Dehydrogenase level greater than 365 U/Litre alone can also predict death from COVID-19 disease 10-18 days ahead with $90 \%$ accuracy y [18].

Several studies have reported various inflammatory and coagulability markers such as serum ferritin, C-Reactive Protein, interleukin-6, fibrinogen, and D-dimer in relation to disease severity and progression, however much consideration has to be paid to the assessments between diabetic and non-diabetic COVID-19 cases.[19] Diabetic patients are more susceptible to intensive care, mechanical ventilation, and deaths due to COVID-19 than those without diabetes owing to low pulmonary function $[3,10]$. 
Measurement of inflammatory markers might support clinicians to monitor and evaluate the severity and prognosis of COVID-19. Associations between elevated inflammatory markers, escalation of respiratory support, and survival in people with COVID-19 indicate the existence of a high-risk inflammatory phenotype. COV-HI might be useful to stratify patient groups in trial design [2].

Our study highlights the association of inflammatory markers with the severity of COVID-19 and helps clinicians monitor and assess the severity as well as prognosis of COVID-19.

\section{Methodology}

This is a retrospective cross-sectional observational study of patients who were tested SARS COV 2 positive. Patient data from August 2020 to September 2020 was collected. The laboratory inflammatory markers, namely Lactate Dehydrogenase, C-reactive protein, D-dimer, Ferritin, were assessed in the selected patients, also their clinical data and demographic details were taken into account. The parameters contributing to the severity including the duration of hospital stay, oxygen requirement, and ICU needs were analyzed. Patients below the age of 14 years, COVID patients only observed for a day, or where multiple laboratory parameters were missing were excluded from the study.

\subsection{Data Collection}

The data was collected from electronic medical records. The study included 303 patients (186 male, 117 female) (Table 1 and 2) between the age of 14 to 90 years, Type 2 Diabetes Mellitus to the ward or ICU at Aster CMI hospital Bengaluru between August 2020 to September 2020. The symptoms at the onset of illness were noted; the frequency of distribution of symptoms and co morbidities in our study group was analysed (as depicted in Figure 1, table 3 and Table 4). Laboratory parameters including the D-dimer, C-reactive protein, and Lactate dehydrogenase (Lactate Dehydrogenase) levels at the time of Type 2 Diabetes Mellitus was collected. Outcome in terms of oxygen requirement (Table 6), the duration of hospital stay (Table 7), and the need for ICU Type 2 Diabetes Mellitus (Table 5) was studied.

\subsection{Statistical analysis}

Data were recorded into a Microsoft Excel data sheet and analysed. Categorical data were represented as proportions and frequencies. Chi-square test was used as a test of significance for various inflammatory markers according to Type 2 Diabetes Mellitus to ICU and oxygen requirement. Continuous data were denoted as mean and standard deviation. A student t-test was used as a test of significance to identify the mean difference between Lactate Dehydrogenase and Ferritin. ANOVA was used to determine the mean difference between D-dimer and C-Reactive Protein as a test of significance.

\subsection{Statistical software}

MS Excel.

\section{Results}

Our study included 303 COVID patients, predominantly middle-aged individuals with majority having some co morbid condition. The most commonly occurring symptoms were fever (62.4\%) followed by cough (47.5\%), body ache (22.8\%), breathlessness (16.5\%), and change in stool consistency (11.6\%), headache $(11.2 \%)$, sore throat $(7.6 \%)$, loss of taste and smell (5.9\%), abdominal pain (2\%), and altered sensorium (1.7\%).

Table 1 Distribution of subjects according to gender

\begin{tabular}{|c|c|c|}
\hline Gender & Frequency & Percent \\
\hline Male & 186 & 61.4 \\
\hline Female & 117 & 38.6 \\
\hline Total & 303 & 100.0 \\
\hline
\end{tabular}




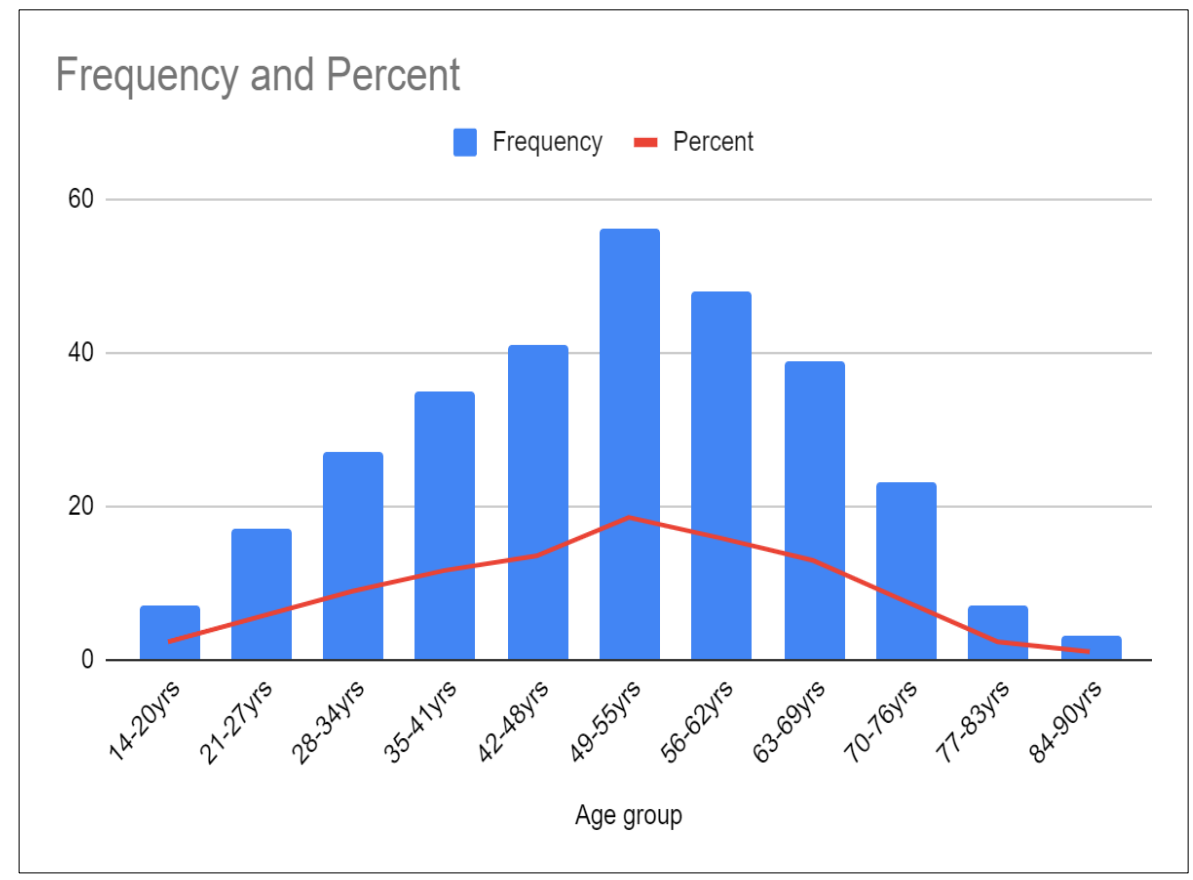

Figure 1 Distribution of subjects according to age group

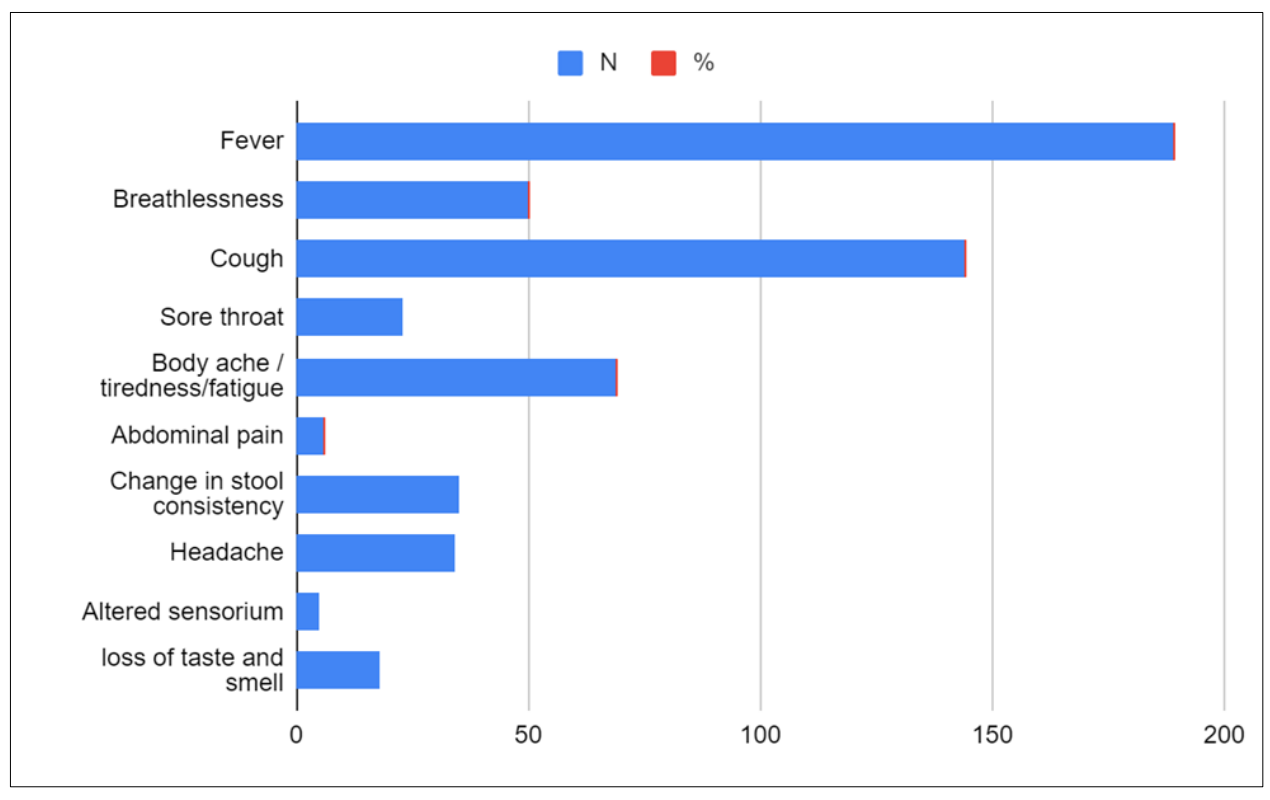

Figure 2 Frequency Distribution of symptoms

The most commonly occurring symptoms were fever (62.4\%) followed by cough (47.5\%), body ache (22.8\%), breathlessness (16.5\%), and change in stool consistency (11.6\%), headache (11.2\%), sore throat (7.6\%), loss of taste and smell (5.9\%), abdominal pain (2\%), and altered sensorium (1.7\%). 
Table 2 Frequency Distribution of comorbidities

\begin{tabular}{|c|c|c|}
\hline & $\mathbf{N}$ & $\%$ \\
\hline Hypertension & 102 & $33.7 \%$ \\
\hline Type 2 Diabetes Mellitus & 113 & $37.3 \%$ \\
\hline Chronic Kidney Disease & 5 & $1.7 \%$ \\
\hline Coronary artery Disease & 11 & $3.6 \%$ \\
\hline Hypertension +Type 2 Diabetes Mellitus & 59 & $19.5 \%$ \\
\hline Hypertension +Type 2 Diabetes Mellitus & 5 & $1.7 \%$ \\
\hline Hypertension Coronary Heart Disease & 8 & $2.6 \%$ \\
\hline $\begin{array}{l}\text { Hypertension +Type } 2 \text { Diabetes Mellitus } \\
\text { Chronic Kidney Disease+hypothyroid }\end{array}$ & 9 & $3.0 \%$ \\
\hline $\begin{array}{l}\text { Hypertension +Type } 2 \text { Diabetes Mellitus } \\
+ \text { +Chronic Kidney Disease }\end{array}$ & 59 & $19.5 \%$ \\
\hline $\begin{array}{l}\text { Hypertension +Type } 2 \text { Diabetes Mellitus } \\
+ \text { Chronic Kidney Disease }\end{array}$ & 3 & $1.0 \%$ \\
\hline $\begin{array}{l}\text { Type } 2 \text { Diabetes Mellitus+Coronary } \\
\text { Heart Disease }\end{array}$ & 10 & $3.3 \%$ \\
\hline Chronic Kidney Disease+Coronary Heart Disease & 1 & $0.3 \%$ \\
\hline $\begin{array}{l}\text { Hypertension +Type } 2 \text { Diabetes Mellitus + } \\
\text { Coronary Heart Disease }\end{array}$ & 7 & $2.3 \%$ \\
\hline $\begin{array}{l}\text { Hypertension+Chronic Kidney Disease+ } \\
\text { Coronary Heart Disease }\end{array}$ & 1 & $0.3 \%$ \\
\hline $\begin{array}{l}\text { Type } 2 \text { Diabetes Mellitus +Chronic Kidney Disease+ } \\
\text { Coronary Heart Disease }\end{array}$ & 1 & $.3 \%$ \\
\hline $\begin{array}{l}\text { Hypertension+Type } 2 \text { Diabetes Mellitus+ } \\
\text { Chronic Kidney Disease } \\
\text { +Coronary Heart Disease }\end{array}$ & 1 & $.3 \%$ \\
\hline Thyroid & 29 & $9.6 \%$ \\
\hline Transient Ischemia Attack & 2 & $.7 \%$ \\
\hline
\end{tabular}


Table 3 Comparison of various inflammatory markers according to admission to ICU

\begin{tabular}{|c|c|c|c|c|c|c|}
\hline & & \multicolumn{4}{|c|}{ Shifted to the ICU } & \multirow[t]{3}{*}{ P-value } \\
\hline & & \multicolumn{2}{|l|}{ No } & \multicolumn{2}{|c|}{ Yes } & \\
\hline & & $\mathbf{N}$ & $\%$ & $\mathbf{N}$ & $\%$ & \\
\hline \multirow{2}{*}{$\begin{array}{l}\text { Lactate } \\
\text { Dehydrogenase }\end{array}$} & $<234$ & 133 & $50.8 \%$ & 7 & $29.2 \%$ & \multirow[t]{2}{*}{0.054} \\
\hline & $>234$ & 129 & $49.2 \%$ & 17 & $70.8 \%$ & \\
\hline \multirow[t]{3}{*}{ D dimer } & $0-500$ & 77 & $27.8 \%$ & 0 & $0.0 \%$ & \multirow[t]{3}{*}{0.001} \\
\hline & $\begin{array}{l}500- \\
1000\end{array}$ & 41 & $14.8 \%$ & 1 & $3.8 \%$ & \\
\hline & $>1000$ & 159 & $57.4 \%$ & 25 & $96.2 \%$ & \\
\hline \multirow[t]{2}{*}{ Ferritin } & $<230$ & 97 & $35.0 \%$ & 4 & $15.4 \%$ & \multirow[t]{2}{*}{0.05} \\
\hline & $>230$ & 180 & $65.0 \%$ & 22 & $84.6 \%$ & \\
\hline \multirow[t]{3}{*}{ C-Reactive Protein } & $<5$ & 86 & $31.7 \%$ & 5 & $19.2 \%$ & \multirow[t]{3}{*}{0.079} \\
\hline & $5-10$ & 37 & $13.7 \%$ & 1 & $3.8 \%$ & \\
\hline & $>10$ & 148 & $54.6 \%$ & 20 & $76.9 \%$ & \\
\hline
\end{tabular}

There was a statistically significant difference found between admission to ICU and D-dimer ( $p=.001)$. There was no statistically significant difference between admission to ICU and LDH, Ferrin, and CRP values.

Table 4 Comparison of various inflammatory markers according to oxygen requirement

\begin{tabular}{|c|c|c|c|c|c|c|}
\hline & & \multicolumn{4}{|c|}{02 Requirement } & \multirow[t]{3}{*}{ P-value } \\
\hline & & \multicolumn{2}{|c|}{ No } & \multicolumn{2}{|c|}{ Yes } & \\
\hline & & $\mathbf{N}$ & $\%$ & $\mathbf{N}$ & $\%$ & \\
\hline \multirow[t]{2}{*}{ LDH } & $<234$ & 133 & $52.2 \%$ & 7 & $22.6 \%$ & \multirow[t]{2}{*}{0.002} \\
\hline & $>234$ & 122 & $47.8 \%$ & 24 & $77.4 \%$ & \\
\hline \multirow[t]{3}{*}{ D dimer } & $0-500$ & 77 & $28.5 \%$ & 0 & $.0 \%$ & \multirow[t]{3}{*}{$<0.001$} \\
\hline & $500-1000$ & 40 & $14.8 \%$ & 2 & $6.1 \%$ & \\
\hline & $>1000$ & 153 & $56.7 \%$ & 31 & $93.9 \%$ & \\
\hline \multirow[t]{2}{*}{ Ferritin } & $<230$ & 94 & $34.8 \%$ & 7 & $21.2 \%$ & \multirow[t]{2}{*}{0.118} \\
\hline & $>230$ & 176 & $65.2 \%$ & 26 & $78.8 \%$ & \\
\hline \multirow[t]{3}{*}{ CRP } & $<5$ & 86 & $32.6 \%$ & 5 & $15.2 \%$ & \multirow[t]{3}{*}{0.024} \\
\hline & $5-10$ & 36 & $13.6 \%$ & 2 & $6.1 \%$ & \\
\hline & $>10$ & 142 & $53.8 \%$ & 26 & $78.8 \%$ & \\
\hline
\end{tabular}

There was a statistically significant difference found between oxygen requirement and D-dimer $(\mathrm{p}<0.001)$, LDH ( $\mathrm{p}=$ 0.002), and CRP ( $\mathrm{p}=0.024)$.

When the mean duration of hospital stay was compared to inflammatory markers, a statistically significant difference was found. (LDH ( $p=0.002)$; D Dimer, CRP ( $p<0.001$ ); Ferritin ( $p=0.011$ ) ( Table 5). 
Table 5 Comparison of mean hospital stay days according to inflammatory markers

\begin{tabular}{|c|c|c|c|c|}
\hline \multirow{2}{*}{ LDH } & & \multicolumn{2}{|c|}{ Days of Hospital stay } & \multirow{2}{*}{ P-value } \\
\cline { 2 - 4 } & & Mean & SD & \\
\cline { 2 - 4 } & $>234$ & 7.8 & 6.8 & \multirow{2}{*}{0.002} \\
\hline \multirow{2}{*}{ D DIMER } & $>234$ & 10.3 & 6.7 & \\
\cline { 2 - 4 } & $0-500$ & 6.4 & 6.6 & \multirow{2}{*}{$<0.001$} \\
\cline { 2 - 4 } & $500-1000$ & 9.1 & 6.3 & \\
\cline { 2 - 4 } & $>1000$ & 10.0 & 6.7 & \\
\hline \multirow{2}{*}{ Ferritin } & $<230$ & 7.5 & 7.0 & \multirow{2}{*}{0.011} \\
\cline { 2 - 4 } & $>230$ & 9.6 & 6.5 & \\
\hline \multirow{2}{*}{ CRP } & $<5$ & 6.7 & 6.3 & \multirow{2}{*}{$<0.001$} \\
\cline { 2 - 4 } & $5-10$ & 7.5 & 5.7 & \\
\cline { 2 - 4 } & $>10$ & 10.5 & 6.9 & \\
\hline
\end{tabular}

\section{Discussion}

COVID 19 is a disease spreading rampantly and associated with its transmission mode, contributing to increased morbidity. Therefore, identifying and picking up the severe cases at the earliest is essential to reduce the ongoing burden on the healthcare systems. Hence, by looking at the inflammatory markers most commonly used during COVID 19 , we have concluded how predictive these are in determining the morbidity and risk of shifting a patient to the ICU.

CRP is a nonspecific acute phase reactant, readily available marker and cost-effective, which can be utilised to determine the severity of COVID 19. The levels of CRP vary among age, gender, lipid profile, smoking status and BMI20. CRP levels of more than $100 \mathrm{mg} / \mathrm{dl}$ have been identified as a predictor of mortality in deciding the length of ICU stay and 30-day mortality ${ }^{21}$. Studies have also shown the utility of CRP in MERS, H1N1, etc., in predicting mortality 22-24.

According to Yao $\mathrm{Y}$ et al. ${ }^{25}$, D dimer can be used to predict severity and in-hospital mortality in patients with COVID 19. The study was a retrospective study that classified patients as per the severity of CT chest, $\mathrm{O}_{2}$ index found the D-dimer $>2.0 \mathrm{mg} / \mathrm{L}$ at admission was the only variable linked with increased odds of mortality. D-dimer elevation ( $\geq 0.50 \mathrm{mg} / \mathrm{L})$ was seen in $74.6 \%(185 / 248)$ of the patients.

Our study found that considering inpatient morbidity parameters, such as $\mathrm{O} 2$ requirement, ICU need, and the number of days of hospital stay. On comparing inflammatory markers, we found a statistical difference between the inflammatory markers except for Ferritin and the oxygen requirement, all the inflammatory markers, and the number of days of stay in the hospital. Between ICU admissions, D-dimer was found to have a statistical significance.

A study conducted by Yan Y et al. ${ }^{26}$ in terms of determining severity in COVID 19, one of which was a metanalysis which showed that CRP levels contributed C-reactive protein D-dimer $>2.0 \mathrm{mg} / \mathrm{L}$ at admission was the only variable related with increased odds of mortality, as seen in our study where the results were statistically significant.

There was a statistically significant difference found between oxygen requirement and D-dimer $(\mathrm{p}<0.001)$, LDH ( $\mathrm{p}=$ 0.002 ), and CRP ( $p=0.024$ ) similar to the studies conducted by Kishan $\mathrm{H}$ et al. ${ }^{27}$, Huang I et al. ${ }^{28}$, Yao Y et al. ${ }^{24}$, and Channappanavar R et al.29.

Garcia et al. ${ }^{30}$ found Significant differences in LDH levels were found between the no severe and severe groups. It was demonstrated that an increase or decrease of LDH was indicative of radiographic progress or improvement $(P<0.05)$. The level of LDH in the individual groups varied. A statistically significant higher level of LDH was also observed in terms of ICU vs none 
ICU patients and nonsurvivable patient's vs survival patients.

In the first 7 days, the maximum CRP value was significantly higher in patients who died than those who survived. The gradient of variation in daily CRP levels within the first 7 days was also lesser in patients who survived than those who died ${ }^{31}$. This was similar to the findings of our study; the comparison of inflammatory markers with the mean duration of hospital stay revealed a statistically significant difference. (LDH $(p=0.002)$; D-dimer, CRP $(p<0.001)$; and Ferritin $(\mathrm{p}=0.011)$.

In a meta-analysis study conducted by Szarpak L et al. ${ }^{32}$, lactate dehydrogenase level can be used to predict mortality and severity in COVID -19. Furthermore, a statistically significant higher level of LDH was also observed in terms of ICU vs Non-ICU (95\% CI: 195.46, 350.51; $p<0.001)$.

\section{Added value to our study}

Our study demonstrated the effectiveness of various inflammatory markers in determining the illness's various outcomes. By doing this study, we have also determined which inflammatory markers contributed to each specific outcome considered in determining the severity of COVID 19.

Thus, through the study, we hope to simulate further studies from various networks that can help predict the need for ICU using these specific parameters commonly done and help stratify patients early to reduce the healthcare burden.

\section{Limitations of the study}

This study considers the initial values of inflammatory markers', not their dynamic changes; hence, the changes have not been documented. Since data is from a single institute, there may be discrepancies and low sensitivity in its widespread application. Patients included in the study have been earlier treated with steroids, antibiotics, and antivirals.

\section{Conclusion}

There is a significant association between the increasing levels of D-dimer and all the outcome measures considered. The D dimer, $\mathrm{LDH}$, and CRP help predict oxygen requirement, and all the inflammatory markers can predict the number of days of stay in the hospital.

\section{Compliance with ethical standards}

\section{Acknowledgments}

The authors wish to thank Dr Swathi S Balachandra, Primary Care Physician and researcher, PCMH Restore Health, Bangalore; Sanwal Shah Kalia, Mentor, Acharya Institute of Technology; Dr Chethan T K, Assistant professor, Department of Community medicine, CI MS, Chamrajnagar and Dr Swetha Alahari and Chetna Mohan for technical help.

\section{Disclosure of conflict of interest}

The authors have no Conflicts of interest to be disclosed

\section{Statement of ethical approval}

Approval from the hospital was taken.

\section{References}

[1] Peiris JS, Chu CM, Cheng VC, Chan KS,Hung IF, Poon LL, Law KI, Tang BS, Hon TY, Chan CS, Chan KH, Ng JS, Zheng BJ, Ng WL, Lai RW Guan, Y Yuen KY. HKU/UCH SARS study group. Clinical progression and viral load in a community outbreak of coronavirus associated SARS pneumonia: a prospective study. Lancet. 2003; 361: 176772.

[2] Manson JJ, Crooks C, Naja M, Ledlie A, Goulden B, Liddle T, Khan E, Mehta P, Martin-Gutierrez L, Waddington KE, Robinson GA, Ribeiro Santos L, McLoughlin E, Snell A, Adeney C, Schim van der Loeff I, Baker KF, Duncan C, 
Hanrath AT, Lendrem BC, Tattersall RS. COVID-19-associated hyperinflammation and escalation of patient care: a retrospective longitudinal cohort study. The Lancet. Rheumatology. 2020; 2(10): e594-e602.

[3] Tanaka T, Narazaki M, Kishimoto T. Immunotherapeutic implications of IL-6 blockade for cytokine storm. Immunotherapy. 2016; 8(8): 959-70.

[4] Zhang Y, Li H, Zhang J, Cao Y, Zhao X, Yu N, Gao Y, Ma J, Zhang H, Zhang J, Guo X, Liu X. The clinical characteristics and outcomes of patients with diabetes and secondary hyperglycemia with coronavirus disease 2019: A singlecentre, retrospective, observational study in Wuhan. Diabetes Obes Metab. 2020; 22(8): 1443-1454.

[5] Li Y, Zhao K, Wei H, Chen W, Wang W, Jia L, Liu Q, Zhang J, Shan T, Peng Z, Liu Y, Yan X. Dynamic relationship between D-dimer and COVID-19 severity. Br J Haematol. 2020; 190(1): e24-e27.

[6] Qin C, Zhou L, Hu Z, Zhang S, Yang S, Tao Y, Xie C, Ma K, Shang K, Wang W, Tian DS. Dysregulation of Immune Response in Patients with Coronavirus 2019 (COVID-19) in Wuhan, China. Clin Infect Dis. 2020; 71(15): $762-768$.

[7] Huang KJ, Su IJ, Theron M, Wu YC, Lai SK, Liu CC, Lei HY. An interferon-gamma related cytokine storm in SARS patients. J Med Virol. 2005; 75(2): 185-94.

[8] Pieracci FM, Barie PS. Iron and the risk of infection. Surg Infect (Larchmt). 2005; S41-6.

[9] Wooldridge KG, Williams PH. Iron uptake mechanisms of pathogenic bacteria. FEMS Microbiol Rev. 1993; 12(4): 325-48.

[10] Lin Z, Long F, Yang Y, Chen X, Xu L, Yang M. Serum ferritin as an independent risk factor for severity in COVID-19 patients. J Infect. 2020; 81(4): 647-679.

[11] Luo X, Zhou W, Yan X, Guo T, Wang B, Xia H, Ye L, Xiong J, Jiang Z, Liu Y, Zhang B, Yang W. Prognostic Value of CReactive Protein in Patients With Coronavirus 2019. Clin Infect Dis. 2020; 71(16): 2174-2179.

[12] Mahmoud Sadeghi-Haddad-Zavareh, Masomeh Bayani, Mehran Shokri, Soheil Ebrahimpour, Arefeh Babazadeh, Rahele Mehraeen, Emadoddin Moudi, Ali Rostami, Mohammad Barary, Akram Hosseini, Ali Bijani, Mostafa Javanian. C-Reactive Protein as a Prognostic Indicator in COVID-19 Patients", Interdisciplinary Perspectives on Infectious Diseases. Interdisciplinary Perspectives on Infectious Diseases. 2021.

[13] Querol-Ribelles JM, Tenias JM, Grau E, Querol-Borras JM, Climent JL, Gomez E, Martinez I. Plasma d-dimer levels correlate with outcomes in patients with community-acquired pneumonia. Chest. 2004; 126(4): $1087-9$.

[14] Hsu P.P., Sabatini D.M. Cancer cell metabolism: Warburg and beyond. Cell. 2008; 134(5): 703-707.

[15] Martinez-Outschoorn UE, Prisco M, Ertel A. Ketones and lactate increase cancer cell "stemness," driving recurrence, metastasis and poor clinical outcome in breast cancer: achieving personalised medicine via metabolo-genomics. Cell Cycle. 2011; 10(8): 1271-1286.

[16] Henry BM, Aggarwal G, Wong J, et al. Lactate dehydrogenase levels predict coronavirus disease 2019 (COVID-19) severity and mortality: A pooled analysis. Am J Emerg Med. 2020; 38(9): 1722-1726.

[17] Manson JJ, Crooks C, Naja M, Ledlie A, Goulden B, Liddle T, Khan E, Mehta P, Martin-Gutierrez L, Waddington KE, Robinson GA, Ribeiro Santos L, McLoughlin E, Snell A, Adeney C, Schim van der Loeff I, Baker KF, Duncan CJA, Hanrath AT, Lendrem BC, De Soyza A, Peng J, J'Bari H, Greenwood M, Hawkins E, Peckham H, Marks M, Rampling T, Luintel A, Williams B, Brown M, Singer M, West J, Jury EC, Collin M, Tattersall RS. COVID-19-associated hyperinflammation and escalation of patient care: a retrospective longitudinal cohort study. Lancet Rheumatol. Oct 2020; 2(10): e594-e602.

[18] Joynt GM Wu WKK Understanding COVID-19: what does viral RNA load really mean? Lancet Infect Dis. 2020; 20: 635-636.

[19] Kermali M, Khalsa RK, Pillai K, Ismail Z, Harky A. The role of biomarkers in diagnosis of COVID-19 - A systematic review. Life Sci. 1 Aug 2020; 254: 117788.

[20] Brull D, Serrano N, Zito F, Jones L, Montgomery H, Rumley A. Human CRP Gene Polymorphism Influences CRP Levels. Arteriosclerosis, Thrombosis, and Vascular Biology. 2003; 23(11): 2063-2069.

[21] Sharifpour M, Rangaraju S, Liu M, Alabyad D, Nahab FB, Creel-Bulos CM, et al. C Reactive protein as a prognostic indicator in hospitalised patients with COVID-19. PLoS ONE. 2020; 15(11).

[22] Wang J-T, Sheng W-H, Fang C-T, et al. Clinical manifestations, laboratory findings, and treatment outcomes of SARS patients. Emerg Infect Dis 2004; 10(5): 818-24. 
[23] Ko J-H, Park GE, Lee JY, et al. Predictive factors for pneumonia development and progression to respiratory failure in MERS-CoV, infected patients. J Infect. 2016; 73(5): 468-75.

[24] Vasileva D, Badawi A. C-reactive protein as a biomarker of severe H1N1 influenza. Inflamm Res. 2019; 68(1): 3946.

[25] Yao Y, Cao J, Wang Q. D-dimer as a biomarker for disease severity and mortality in COVID-19 patients: a casecontrol study. J intensive care. 2020; 8(49).

[26] Yan Y, Yang Y, Wang F, Ren H, Zhang S, Shi X, Yu X, Dong K. Clinical characteristics and outcomes of patients with severe covid-19 with diabetes. BMJ Open Diabetes Res Care. Apr 2020; 8(1).

[27] Hari Kishan J, Karthikeya Byalya, V. Sharvan Kumar. Serum ferritin, serum LDH and d-dimer in correlation with the outcome in Covid-19. Int J Med Res Rev. Feb 2021.

[28] Huang I, Pranata R, Lim MA, Oehadian A, Alisjahbana B. C-reactive protein, procalcitonin, D-dimer, and Ferritin in severe coronavirus disease-2019: a meta-analysis. Ther Adv Respir Dis. Jan-Dec 2020; 14.

[29] Channappanavar R, Perlman S. Pathogenic human coronavirus infections: causes and consequences of cytokine storm and immunopathology. Semin Immunopathol. Jul 2017; 39(5): 529-539.

[30] García-Salido A, de Carlos Vicente JC, Belda Hofheinz S. et al. Severe manifestations of SARS-CoV-2 in children and adolescents: from COVID-19 pneumonia to multisystem inflammatory syndrome: a multicentre study in pediatric intensive care units in Spain. Crit Care. 2020; 24.

[31] Zeng F, Huang Y, Guo Y, Yin M, Chen X, Xiao L, Deng G. Association of inflammatory markers with the severity of COVID-19: A meta-analysis. International Journal of infectious diseases: IJID. 2020; 96: 467-474.

[32] Szarpak L, Ruetzler K, Safiejko K, et al. Lactate dehydrogenase level as a COVID-19 severity marker [published online ahead of print, 2020 Nov 15]. Am J Emerg Med. 2020; S0735- 6757(20): 31034-2. 